\title{
Effect of shielding conditions on bead profile and melting behaviour in laser powder bed fusion additive manufacturing
}

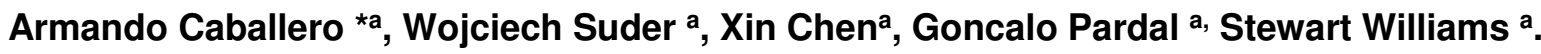 \\ a Welding Engineering and Laser Processing Centre, Cranfield University, Cranfield MK43 OAL, UK. \\ *corresponding author: E-mail address: a.e.caballeroramos@cranfield.ac.uk
}

\begin{abstract}
A series of experiments were performed using a 500W continuous wave fibre laser on a single powder bed layer using different processing variables. The aim was to investigate the effect of different shielding conditions on melting behaviour and bead profile in laser powder bed fusion (PBF). Through high-speed imaging, it was found that under an argon atmosphere a strong plasma plume is generated from the meltpool. Laser beam-plasma plume interactions caused strong instabilities during melting, including laser wandering, track instability and continuous fluctuations between melting regimes (conduction and keyhole). Hence, it was not possible to control the profile of the melted tracks under this condition. By using a helium atmosphere, a smaller plasma was obtained, reducing the disruptions caused by laser-plasma interactions. This led to a stable melting regime that allowed control of the melt bead profile. This condition was used to study the effect of laser-material fundamental interaction parameters on the bead geometry in powder bed melting. It was found that during melting of single tracks, the dominant regime of melting is conduction for the range of parameters tested. Penetration and melt width were found to increase with increasing energy density. For longer interaction times, melt widths were found to be up to ten times the size of the beam diameter used. Fluid flow modelling showed that this is due to strong melt flow as consequence of surface tension gradients generated by very high temperature gradients.
\end{abstract}

Keywords: powder bed fusion, plasma plume, argon atmosphere, helium atmosphere, SLM 


\section{Introduction}

Laser powder bed fusion (PBF) is a powder based additive manufacturing (AM) technology that has attracted increasing attention in the recent years. In PBF, high complexity and high resolution parts can be obtained through the selective melting of successive layers of metallic powder using a laser beam [1]. Additional advantages of PBF include improved design flexibility and shorter lead times as compared to traditional technologies [2]. During the powder-laser interaction many physical phenomena take place, making it difficult to control the quality of manufactured parts. Such phenomena include material vaporization and complex gas dynamics, which are known to cause defects on the final component [3]. The most common defects are porosity and lack of fusion, which can compromise the structural integrity of a component. For this reason, the effect of numerous process parameters on the melting behaviour and bead geometry on PBF has been the subject of many investigations in order to minimize the occurrence of such defects.

As a way to mitigate defect formation during PBF, it is useful to establish the correlation between processing conditions and the bead profile obtained. Additionally, the control of bead shape is important because it determines the resolution and layer height achieved in the process. It is known that for laser welding and other AM techniques the shielding conditions used can have an important effect on the melting behaviour, geometry and microstructure of the manufactured parts $[4,5]$. Hence, it is expected that optimizing the shielding atmosphere during PBF could have a significant impact on the process characteristics and can be used as a way to control bead profile and minimize defects.

Several studies have been performed regarding the role of the shielding gas during laser welding, particularly the effect of argon and helium. Most of the published work agree on the fact that laser welding under helium or higher percentages of helium leads to a smaller plasma plume volume and also enhanced melting stability $[6,7,8]$. This has been attributed to the better cooling effect of helium as compared to argon and to its higher ionization potential. Previous works have also come to the conclusion that for $\mathrm{CO}_{2}$ lasers $(\lambda=10.64$ 
$\mu \mathrm{m})$ the total absorption of the laser radiation can be up to $33 \%$ when argon is used and only $5 \%$ when helium is used instead. Hence, it has been reported that, for $\mathrm{CO}_{2}$ laser beam welding, shielding gas composition has an important influence on weld penetration where deeper weld penetration has been obtained by increasing the content of helium $[9,10]$. In contrast, it has been found that for lasers of shorter wavelengths such as YAG, fibre of disk laser $(\lambda=1.064 \mu \mathrm{m})$ the effect of shielding gas on process stability and weld geometry is minor and other parameters such as laser power density are dominant. For example, Kuo and Lin [11] reported that for a fixed set of welding parameters, similar penetration shapes and depths are obtained independently of the shielding gas employed. This is due to the fact that during Nd:YAG laser welding, laser energy absorption in the plume is very weak and therefore the plume volume has a lesser influence on the penetration depth. The effect of different shielding gases on melting stability for fibre laser in combination with small beam size $(\leq 100 \mu \mathrm{m})$, such as the ones commonly used in laser PBF, needs to be further explored.

For additive manufacturing, there has not been much work focused on the role of shielding gas on process characteristics. Bidare et al [12] reported that, in contrast to using argon, a helium atmosphere gives more stable melting that produces a smoother surface finish of the melted tracks, but increased depletion of powder particles away from the processing point was observed. However, this work was mainly focused on the study of PBF under a high pressure argon atmosphere with little attention to melting behaviour and bead geometry. Their work did not show any particular benefit from using high-pressure atmospheres, as compared to atmospheric pressure. Montgomery et al [13] considered the implementation of different shielding gases and their effect on surface finish. It was found that the powder morphology is the controlling factor for the surface finish rather than the gas composition. In other studies, such as Zhou et al [14] and Bidare et al [15], powder melting under vacuum conditions was investigated. The former found reduced porosity in PBF of Ti-6Al-4V while the latter reported a limited reduction in spatter generation at expenses of an increase in 
denudation of the powder. A feasible method to visualize the shielding gas flow during PBF melting has also been covered by Schniedenharn et al [16]. However, the influence of the gas flow and type on the bead profile was not reported.

Knowing the bead geometry that corresponds to a particular set of processing parameters is paramount to develop a robust process for printing of high quality parts. For this reason, many researchers, such as Guo et al [17] and Shi et al [18] have reported the changes of layer height, penetration depth and bead width as a function of laser power and scanning speed. However, most of the work focuses only on processing under argon atmosphere and no alternative gases have been studied. For this reason the effect of processing parameters, such as laser power and scanning speed on bead geometry are investigated in this work when helium is used as shielding gas. Additionally, the potential of increasing deposition rates during PBF has been explored in the present work by the implementation of relatively large beam size and thicker powder layer as compared to commercial systems. As shown previously by Shi et al [18], building rates can be increased up to 9 times by using powders layer and beam sizes around $200 \mu \mathrm{m}$ as compared to commercial equipment. 


\section{Material and Methods}

\subsection{Materials and experimental system}

An in-house developed powder bed fusion test rig was used for this work (Fig. 1). This system is an open architecture design that allows installation of different laser systems and instrumentation. To exclude any source of distortion and instabilities to the projected laser spot by a galvo scanner, a standard welding head was used and the powder bed was moved using a set of high precision x-y linear stages. The powder test rig was enclosed inside an airtight chamber and the oxygen level controlled by using an Microx Ntron oxygen analyser. High-speed imaging of powder processing was captured using a "Phantom" Vision Research camera fitted with a $25 \mathrm{~mm}-\mathrm{f} / 1.4$ lens. The resolution used was $640 \times 480$ pixels at $1000 \mathrm{fps}$. The entire camera was installed inside the chamber to achieve close-up views.
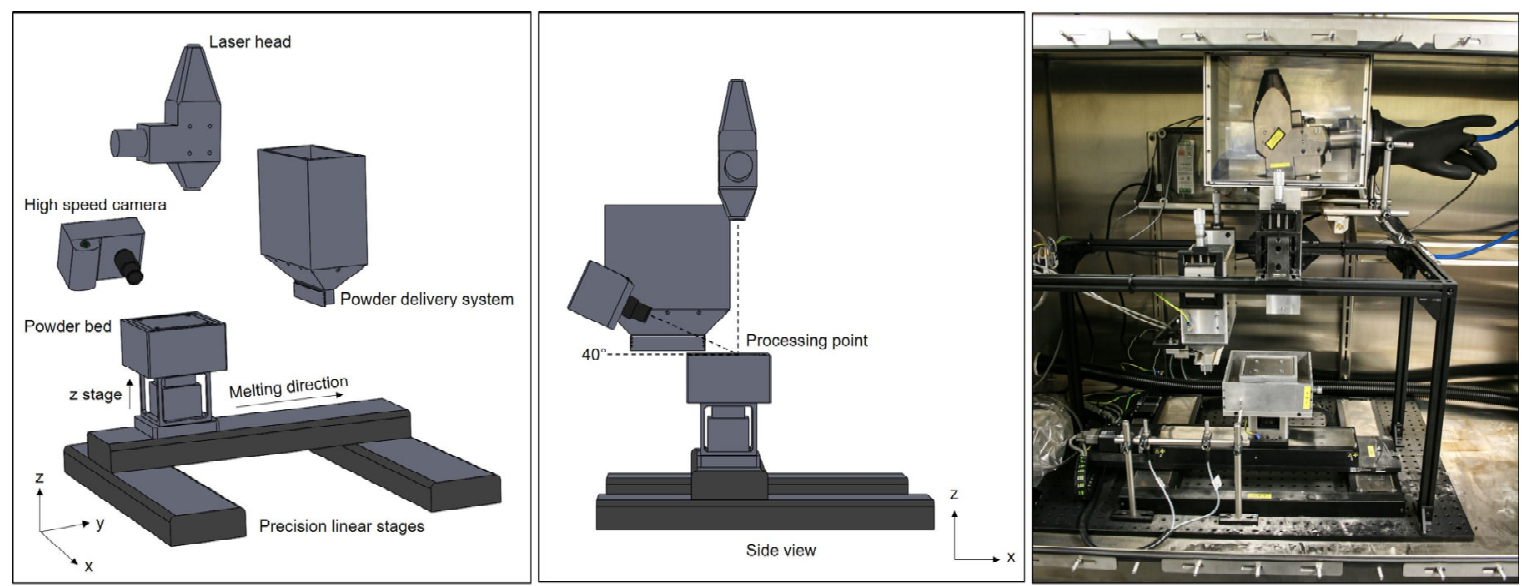

Figure 1. Schematics of powder testing rig and experimental set up.

A continuous wave fibre laser with a maximum power of $500 \mathrm{~W}$ and $\lambda=1064 \mathrm{~nm}$ was used.

The laser beam was delivered through an optical fibre of $50 \mu \mathrm{m}$ diameter, collimated with a $300 \mathrm{~mm}$ focal length lens. Laser light with a Gaussian intensity distribution was used at the focal point giving a D4 $\sigma$ diameter of $100 \mu \mathrm{m}$. All experiments were carried out with the focal point on the surface of the powder layer, or work piece in the case of solid substrate. To prevent back reflection, the laser head was tilted $5^{\circ}$ backwards with respect to the travelling direction. 
For the melting trials, single tracks with a length of $70 \mathrm{~mm}$ were produced. Experiments were performed on powder and solid substrates using the same set of parameters in order to study the melting behaviour in both powder and solid. All powder melting carried out was performed using gas-atomized stainless steel 304L powder with a particle size range of 45$75 \mu \mathrm{m}(\mathrm{d} 10=41.5 \mu \mathrm{m}, \mathrm{d} 50=56.9 \mu \mathrm{m}, \mathrm{d} 90=77.4 \mu \mathrm{m})$. A single powder layer of a thickness of $250 \mu \mathrm{m}$ was used. Powder recoating was achieved by a gravity fed system using a polytetrafluoroethylene scrapper to remove the excess powder. 304 stainless steel with dimensions $12 \mathrm{~mm} \times 85 \mathrm{~mm} \times 85 \mathrm{~mm}$ was used as base plates.

Suder and Williams [19] successfully applied a system-independent approach that allowed identification of the parameters controlling the bead geometry for keyhole laser welding. This approach is based on the implementation of a set of fundamental laser-material interaction parameters. These parameters fully determine the material response to the laser energy independent of the laser system used. In this work, the same approach was followed and power density, interaction time and energy density were used to establish the dependence of bead geometry to process system parameters (laser power, scan speed and laser spot size). These parameters are defined as: Power density, $\mathrm{PD}=P / A_{\text {beam }}\left(\mathrm{kW} / \mathrm{cm}^{2}\right)$, Interaction time, $\mathrm{t}_{\mathrm{i}}=D_{\text {beam }} / T S(\mathrm{~ms})$ and Energy density $\mathrm{E}_{\mathrm{d}}=P D \cdot t_{i}\left(\mathrm{~kJ} / \mathrm{cm}^{2}\right)$ Where $\mathrm{P}$ is the laser power used. $\mathrm{A}_{\text {beam }}$ is the laser beam area projected on the surface. TS is the travel speed and $D_{\text {beam }}$ the laser beam diameter used.

In order to determine how these parameters control the melt profile in laser PBF, a range of power densities of $4800,5500,7100$ and $7700 \mathrm{~kW} / \mathrm{cm}^{2}$ were tested together with interaction times ranging from $0.35 \mathrm{~ms}$ to $4 \mathrm{~ms}$, which corresponds to a scanning speed of $257.1 \mathrm{~mm} / \mathrm{s}$ and $22.5 \mathrm{~mm} / \mathrm{s}$ respectively. Higher scanning speeds were not tested on this work as the motion system of the in-house developed laser powder bed testing rig was based on a set of linear stages that had a maximum movement speed of around $270 \mathrm{~mm} / \mathrm{s}$. The idea of using linear stages instead of a galvo scanner was to avoid changes of the beam shape at the 
processing surface (e.g. elongation of the beam) that can alter the spatial energy distribution and have a significant influence on the resultant melt bead geometry.

\subsection{Testing sequence of different shielding conditions}

Initially, melting of powder and solid was performed using commercially pure argon gas (99.998\% Argon). The argon inert atmosphere was created by pumping the gas into the air tight chamber until a concentration of 300 ppm of oxygen was achieved. This condition will be referred as "global shielding" in this work. No additional flow of gas was induced.

Subsequently in some experiments, additional cross flow shielding on top of the argon global shielding was used to supress the plasma. A Meech A85006 commercially available air knife of $150 \mathrm{~mm}$ long with an argon gas input pressure of 2.5 bar was used to apply a cross flow gas over the powder bed. The stand-off distance between the air knife and the powder bed was $15 \mathrm{~mm}$. This is referred as "global argon with cross flow" set-up. These trials were designed with the aim of determining how localized control of the plasma plume affects melting behaviour and the laser beam-plasma plume interactions. A simplified diagram of the relative position of the cross flow with respect the powder bed is presented in Fig. 2.

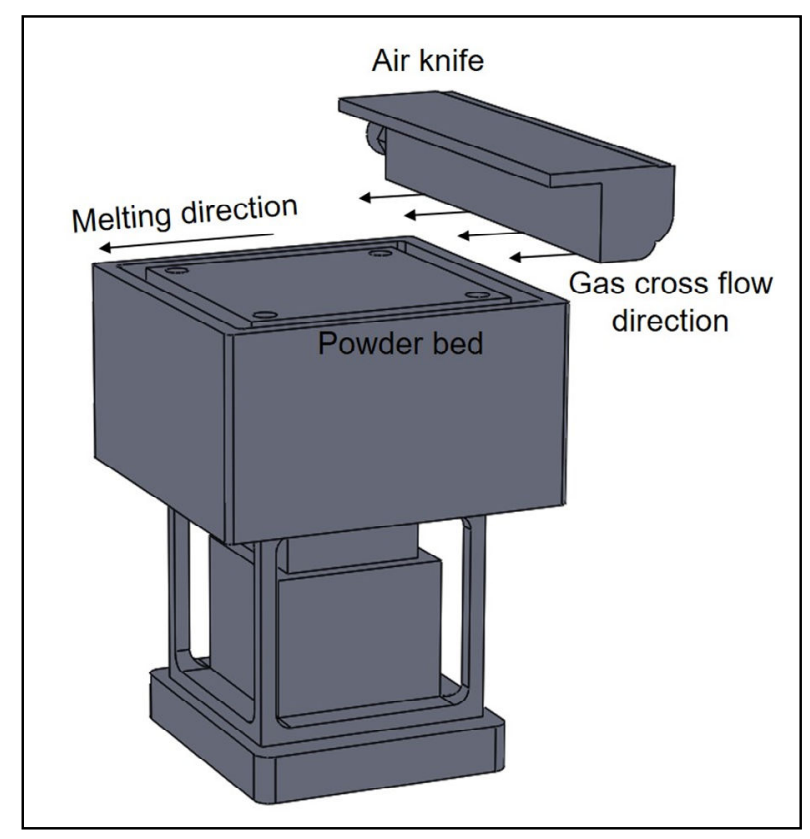

Figure 2. Experimental set up for the gas cross flow. 
In the final experimental stage, melting of powder and solid was performed in a global helium gas inert atmosphere without cross flow, just using global shielding atmosphere with the same processing conditions previously used for the global argon shielding.

\subsection{Sample processing}

Cross-sections of the single tracks were produced to analyse the effect of the different processing conditions on melt geometry. Cross-sections were taken at half way of the length of each track and were mounted in cold resin. In order to stablish the relationship between plasma plume characteristics and bead shape, a careful correlation between the still images and a particular cross section was stablished. In order to achieve this, a particular location of the melt track was located on the still image. Subsequently, the distance from there was calculated using the time interval. On the example presented on this work (Figure 5) the time intervals were equivalent to distances ranging from $1 \mathrm{~mm}$ to $4 \mathrm{~mm}$ from the initial reference point. Hence, it was possible to locate a specific melt track location by carefully grinding away the required amount from the resin mounted sample. Samples were ground and polished following standardized procedures for metallographic preparation of austenitic stainless steel. Etching was performed using Kalling's 2 reagent. Measured dimensions are schematically indicated in Fig. 3, where the aspect ratio is defined as the results of the penetration depth over the bead width. Profiles were imaged using optical microscopy.

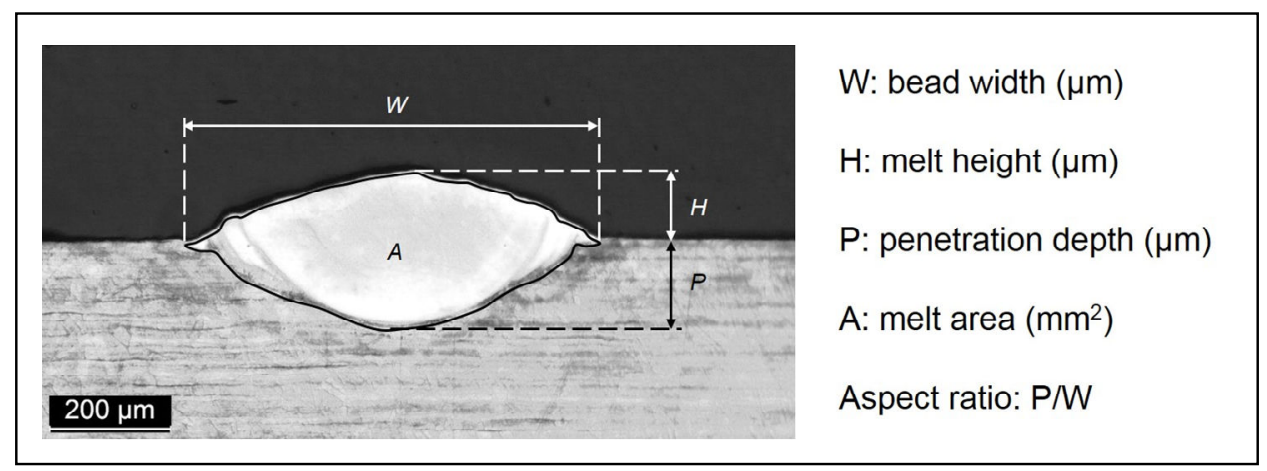

Figure 3. Macrograph of track cross-section defining the measured bead outputs. "Melt height" applies only in the case of powder melting. 


\subsection{Numerical simulation}

To investigate the formation mechanism of certain bead geometries, two-dimensional transient fluid flow numerical simulations were made based on the widely used commercial CFD-software Ansys-Fluent. In the simulations, the single-phase laminar fluid flow module was used together with the heat transfer module due to the near flat bead shape obtained from the experiments. The actual fibre laser beam profile was approximately a Gaussian distribution. Thus, a surface Gaussian heat source considering the travel speed was used in the simulations [20]. To simplify the model, the plume was not incorporated. The absorption coefficient of the laser was set as a fixed value of 0.2 [20]. In the two-dimensional model, wall boundary conditions were employed as the momentum boundary. Marangoni stress was applied on the top side while no-slip boundary conditions were applied on the other three sides. For the energy boundary, the Gaussian surface heat source was applied to the top sides. Besides, the heat convection and radiation with the environment were considered in the other three sides. The convective heat transfer coefficient used was $80 \mathrm{~W}\left(\mathrm{~m}^{2} \mathrm{~K}\right)$ and a surface radiation emissivity of 0.4 . To make the calculation more tractable, only a small size of the specimen, $1.5 \mathrm{~mm} \times 0.6 \mathrm{~mm}$, was employed in the simulations. A small uniform mesh of 0.005 $\mathrm{mm}$, which is only one-tenth of the radius of the laser spot, was used. A fixed time step of $5 \times$ $10^{-7} \mathrm{~s}$ was set to calculate to be great convergence. The melting parameters are the same as that in the experiments (power density of $5500 \mathrm{~kW} / \mathrm{cm}^{2}$ ). The physical parameters of the base plates (304 stainless steel) are shown in Table 1.

Table 1 Physical parameters of 304 stainless steel used in the simulations $[\mathbf{2 1 , 2 2 , 2 3 ]}$

\begin{tabular}{lcc}
\hline Property & Symbol & Value \\
\hline Liquid density $\left(\mathrm{kg} \mathrm{m}^{-3}\right)$ & $\rho_{l}$ & 7200 \\
Liquid specific heat $\left(\mathrm{J} \mathrm{kg}^{-1} \mathrm{~K}^{-1}\right)$ & $C_{p}$ & 760 \\
Liquid heat conductivity $\left(\mathrm{W} \mathrm{m}^{-1} \mathrm{~K}^{-1}\right)$ & $k$ & 35 \\
Solidus temperature $(\mathrm{K})$ & $T_{s}$ & 1670 \\
Liquidus temperature $(\mathrm{K})$ & & 1727
\end{tabular}


Boiling temperature $(\mathrm{K})$

Melting latent $\left(\mathrm{J} \mathrm{kg}^{-1}\right)$

Evaporation latent $\left(\mathrm{J} \mathrm{kg}^{-1}\right)$

Liquid dynamic viscosity $\left(\mathrm{N} \mathrm{m}^{-2} \mathrm{~s}\right)$

Liquid coefficient of thermal expansion $\left(\mathrm{K}^{-1}\right)$

Surface tension temperature coefficient $\left(\mathrm{N} \mathrm{m}^{-1} \mathrm{~K}^{-1}\right)$
$T_{v}$

$L_{m}$

$L_{v}$

$\mu_{l}$

$\beta$

$\frac{d \sigma}{d T}$
$-0.43 \times 10^{-3}$

\section{Results}

\subsection{Argon global shielding}

Cross-sections of some selected melt profiles produced using argon global shielding are presented in Fig. 4. From the images, it can be seen that the behaviour of the melt pool fluctuates in terms of melting regime. That is, for the same power density, melt profile fluctuates between conduction and keyhole regimes as the interaction time is increased. This was found to be the case for both powder and solid melting as shown in Fig. $\mathbf{4 a}$ and Fig. $\mathbf{4 b}$ respectively. Note that the change of process regime and resulting bead shape changed randomly for both cases. In many instances, particularly for longer interaction times, the melt profile width was found to be up to ten times greater than the beam size used. This indicated strong convection in the liquid. 

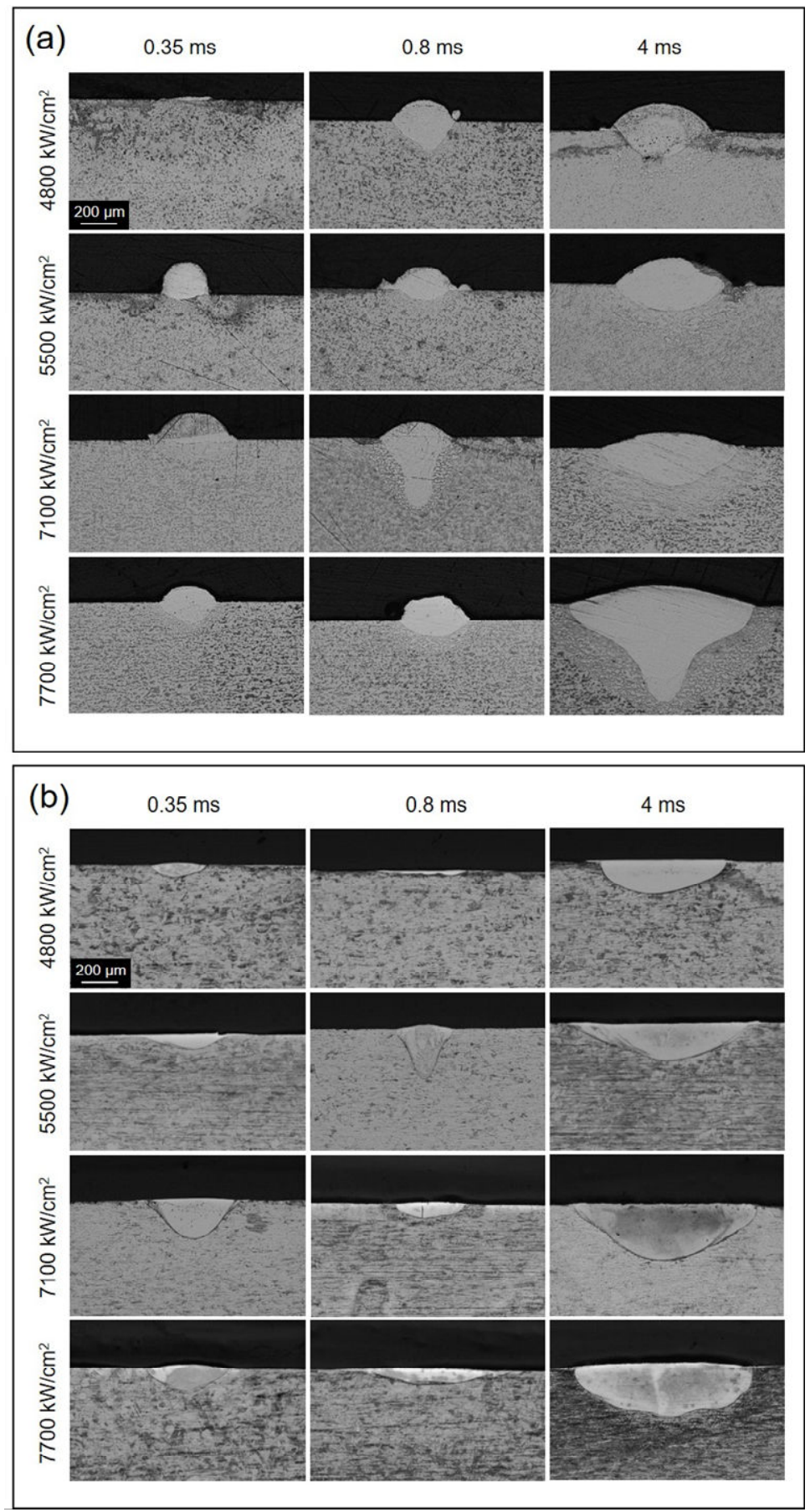

Figure. 4. Selected cross-section from single tracks using argon shielding for different combinations of power densities and interaction times. (a) Powder melting. (b) Solid melting. Beam size: $100 \mu \mathrm{m}$.

Fig 5. (Video Fig 5) shows the relationship between plasma plume behaviour and penetration depth for the same set of parameters. It can be observed that fluctuations in the plume characteristics occur with a change in melting regime. More specifically, it was found that a high intensity plasma plume with high upward directionality is associated with the 
keyhole regime with deep penetration bead profile. While a small visible surface emission corresponds to the conduction regime with a characteristic hemi-spherical bead profile.

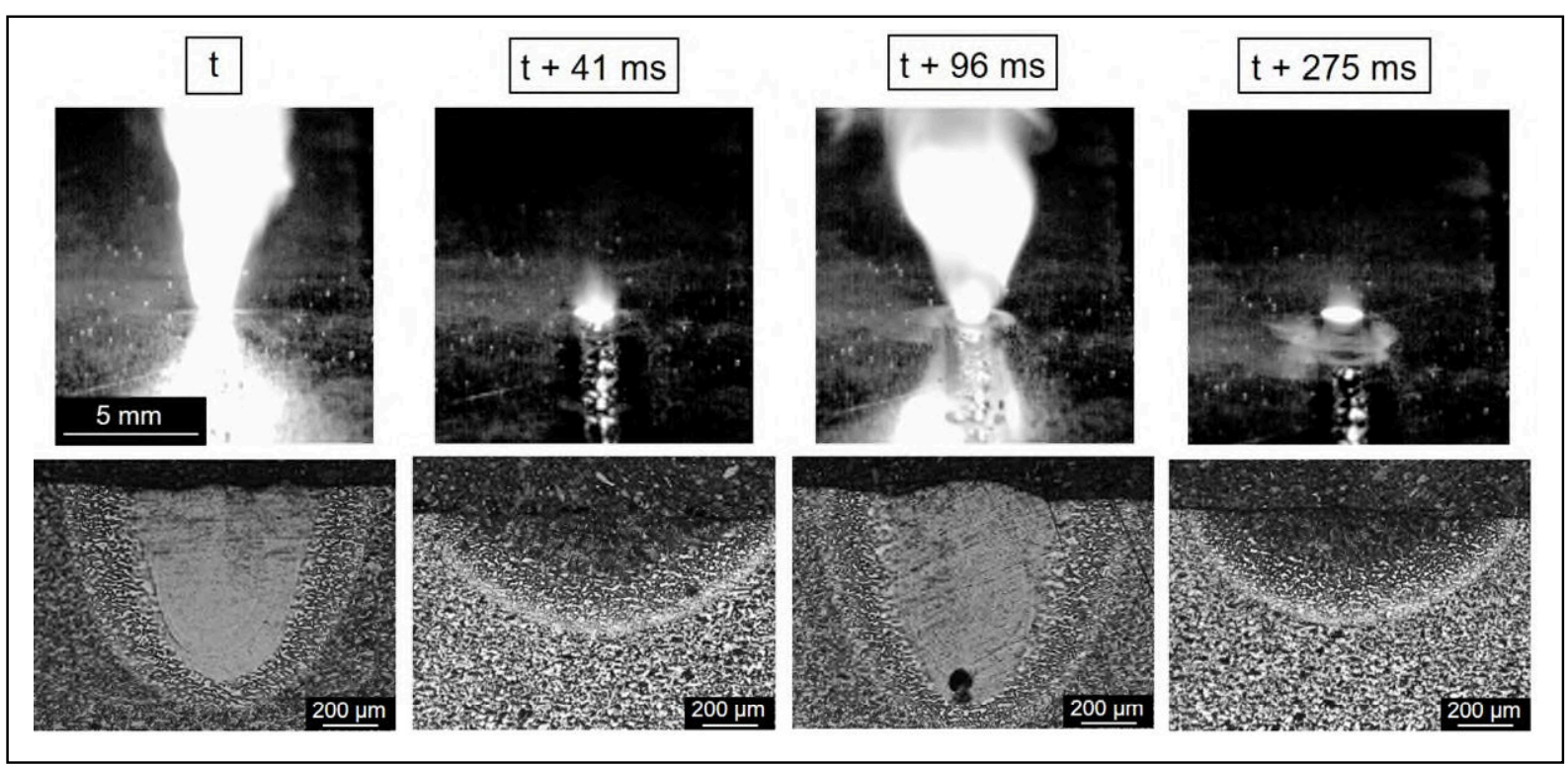

Figure 5. Correlation between plasma plume characteristics and penetration depth for the same track. Power density $7700 \mathrm{~kW} / \mathrm{cm}^{2}$, Interaction time $4 \mathrm{~ms}$, solid melting.

Fig. 6(a)-6(b) (Videos Fig 6 a-c) show stills from the high-speed imaging, highlighting the previously described plasma plume behaviour. Fig. 6(c) provides a different angle view, where the effect of plume fluctuation on the track linearity can be observed. In some instances, the change in plume behaviour is accompanied by wandering of the melt track. These changes in plume characteristics were found to occur at random locations along the melt track. 


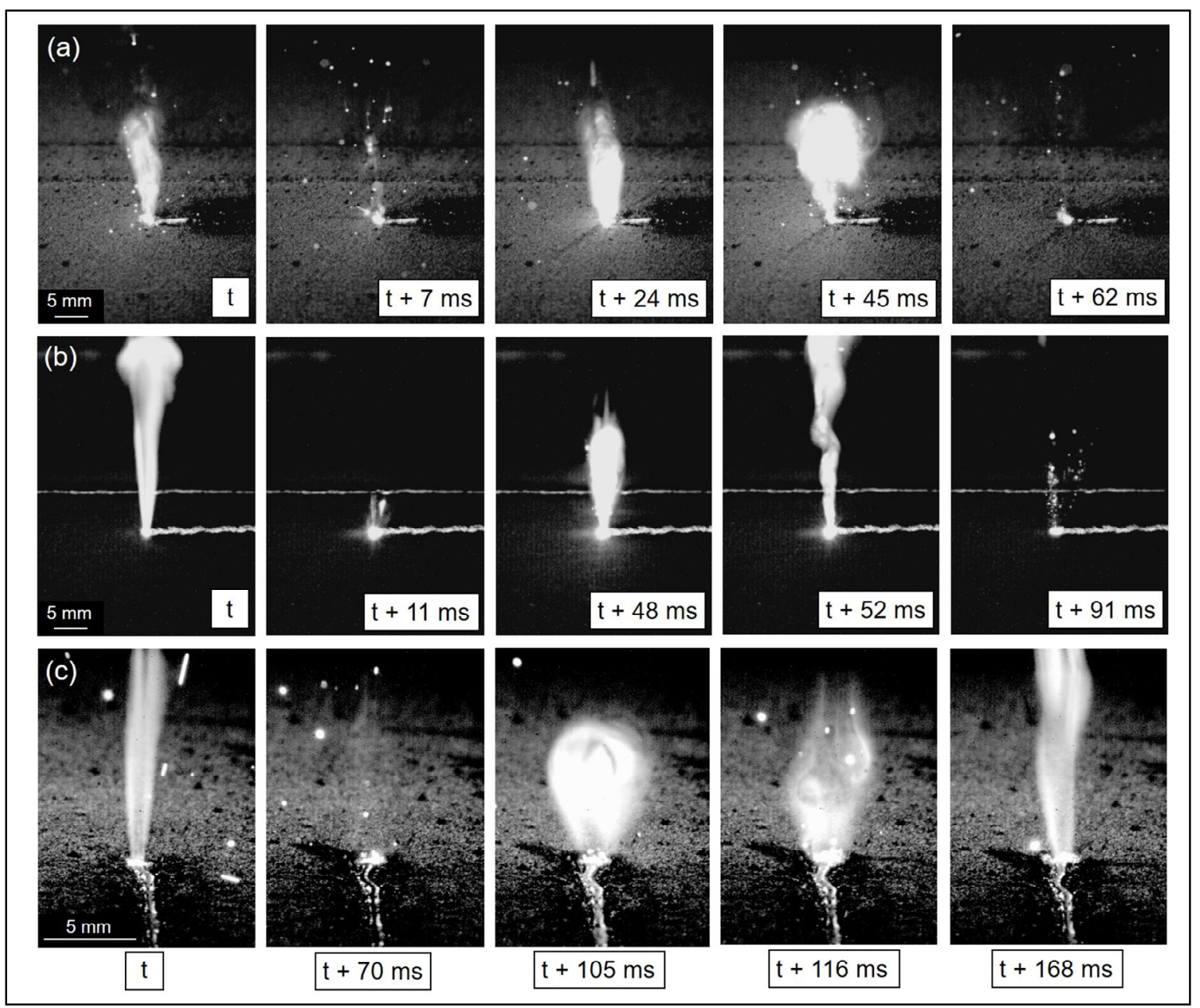

Figure 6. High-speed images for single tracks melting using global argon shielding with a power density of $4800 \mathrm{~kW} / \mathrm{cm} 2$ and an interaction time of $4 \mathrm{~ms}$. (a) Side view of melting of powder. (b) Side view of melting of solid substrate. (c) Front view of melting on powder.

\subsection{Global argon shielding with cross flow}

High-speed imaging of powder melting performed with an argon cross flow set-up together with global argon shielding for two different interaction times are shown in Fig 7 (Videos

Fig 7). When a gas cross flow was added, fewer fluctuations of the plasma plume was observed, leading to more stable melting. Additionally, the size and intensity of the laser induced plasma decreased in the presence of the cross flow. 

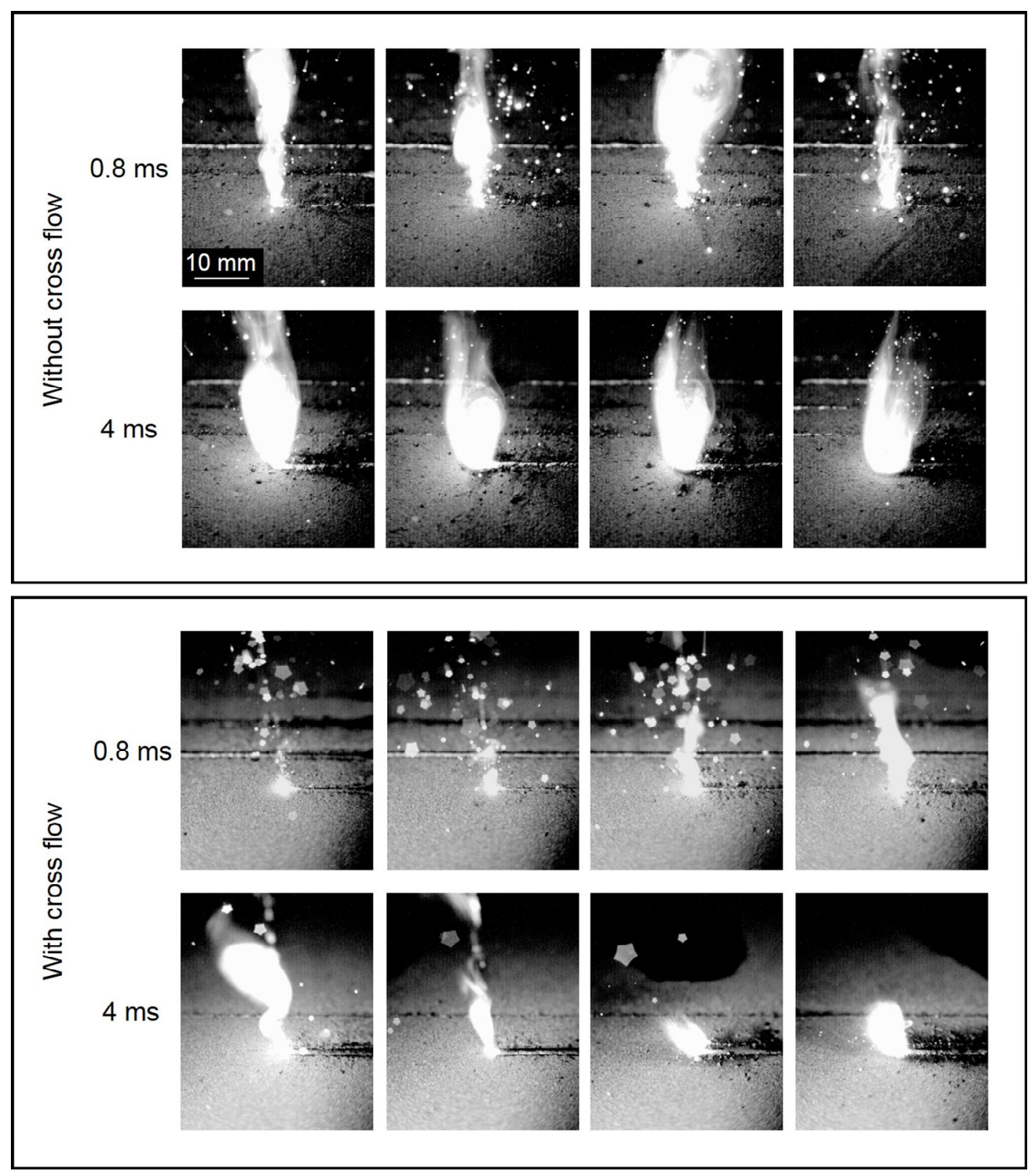

Figure. 7. High speed imaging of powder melting without and with argon gas cross flow and global shielding for two different interaction times. The time intervals between snapshots are $155 \mathrm{~ms}$ and 775 $\mathrm{ms}$ for interaction times of $0.8 \mathrm{~ms}$ and $4 \mathrm{~ms}$ respectively. Power density: $7700 \mathrm{~kW} / \mathrm{cm}^{2}$.

\subsection{Helium global shielding}

In the next experiment, global helium was used. Fig. $\mathbf{8}$ shows selected cross-sections from single tracks produced under global helium shielding and with the same parameters as in Fig. 4. A consistent melting regime can be identified in contrast to the profiles obtained using global argon shielding. In this case, the conduction melting regime is present with no fluctuations between conduction and keyhole. This behaviour is verified for both powder and 
solid melting. It can also be seen that penetration depth increases with power density and interaction time. This gives foundation to the potential development of processing algorithms for control of bead profile and hence resolution, quality and remelting in powder melting. The width is fixed and proportional to the spot size for short interaction times, but then increases significantly, as the interaction times get longer. A detailed look to Fig. 8(a) reveals that no powder consolidation was obtained for power densities of $7100 \mathrm{~kW} / \mathrm{cm}^{2}$ and $7700 \mathrm{~kW} / \mathrm{cm}^{2}$ when short interaction times were used. The maximum bead width was found to be around $1200 \mu \mathrm{m}$ for helium global shielding, while the maximum width for argon shielding was around $1000 \mu \mathrm{m}$. This means that even wider beads are obtained when using helium as compared to argon shielding gas, which can be attributed to strong convection in the liquid metal. 

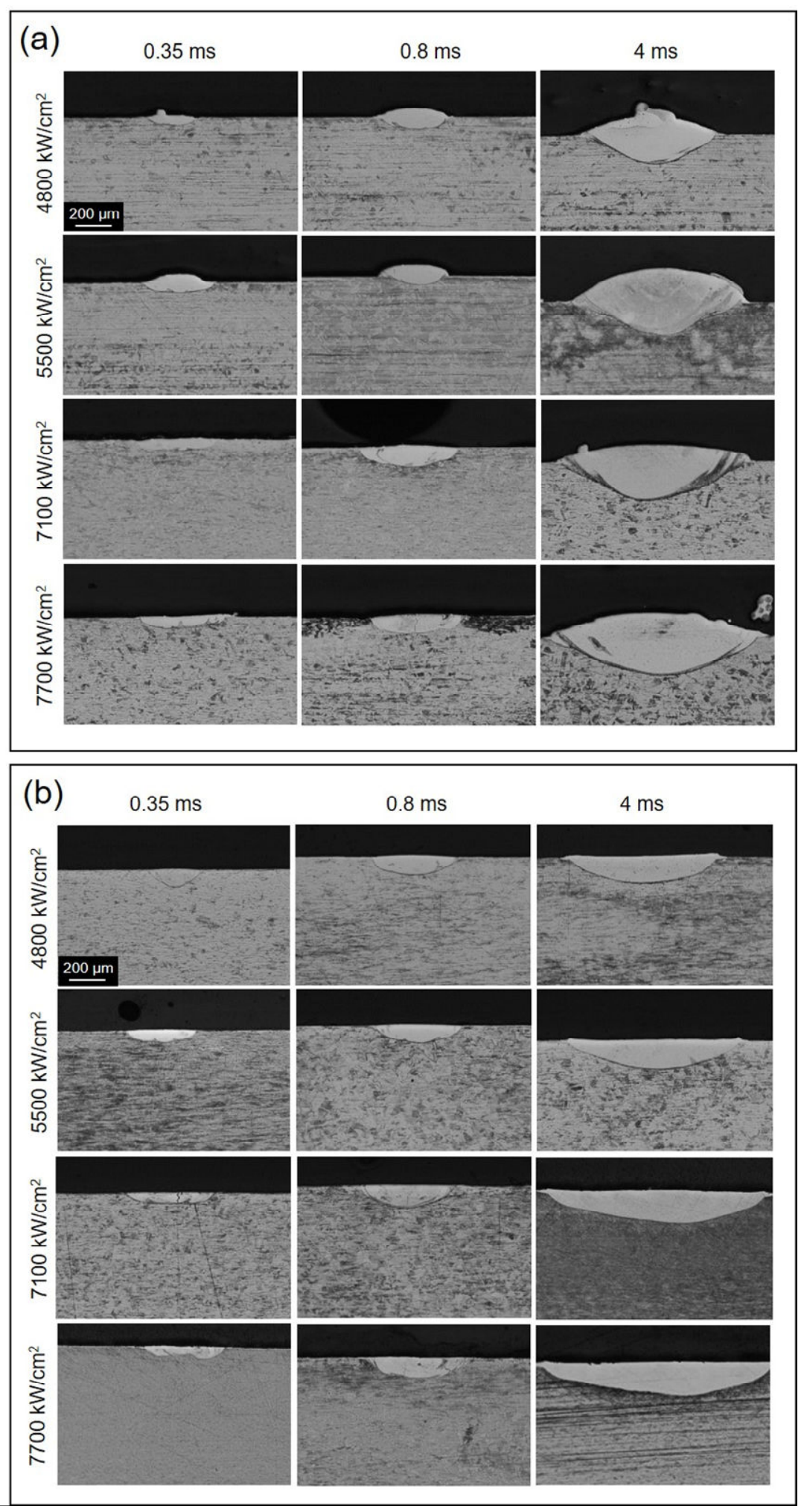

Figure. 8. Selected cross-sections from single tracks using global helium shielding for different combinations of power densities and interaction times. (a) Powder melting. (b) Solid melting. Beam size: $100 \mu \mathrm{m}$. 
During melting under a helium atmosphere, high-speed imaging revealed that the plasma plume is smaller and of less intensity compared to melting under argon atmosphere for the same set of processing parameters (Fig. 9 and Videos Fig 9 a-d ). Additionally, less plasma instability and fluctuation are seen for helium compared to argon.
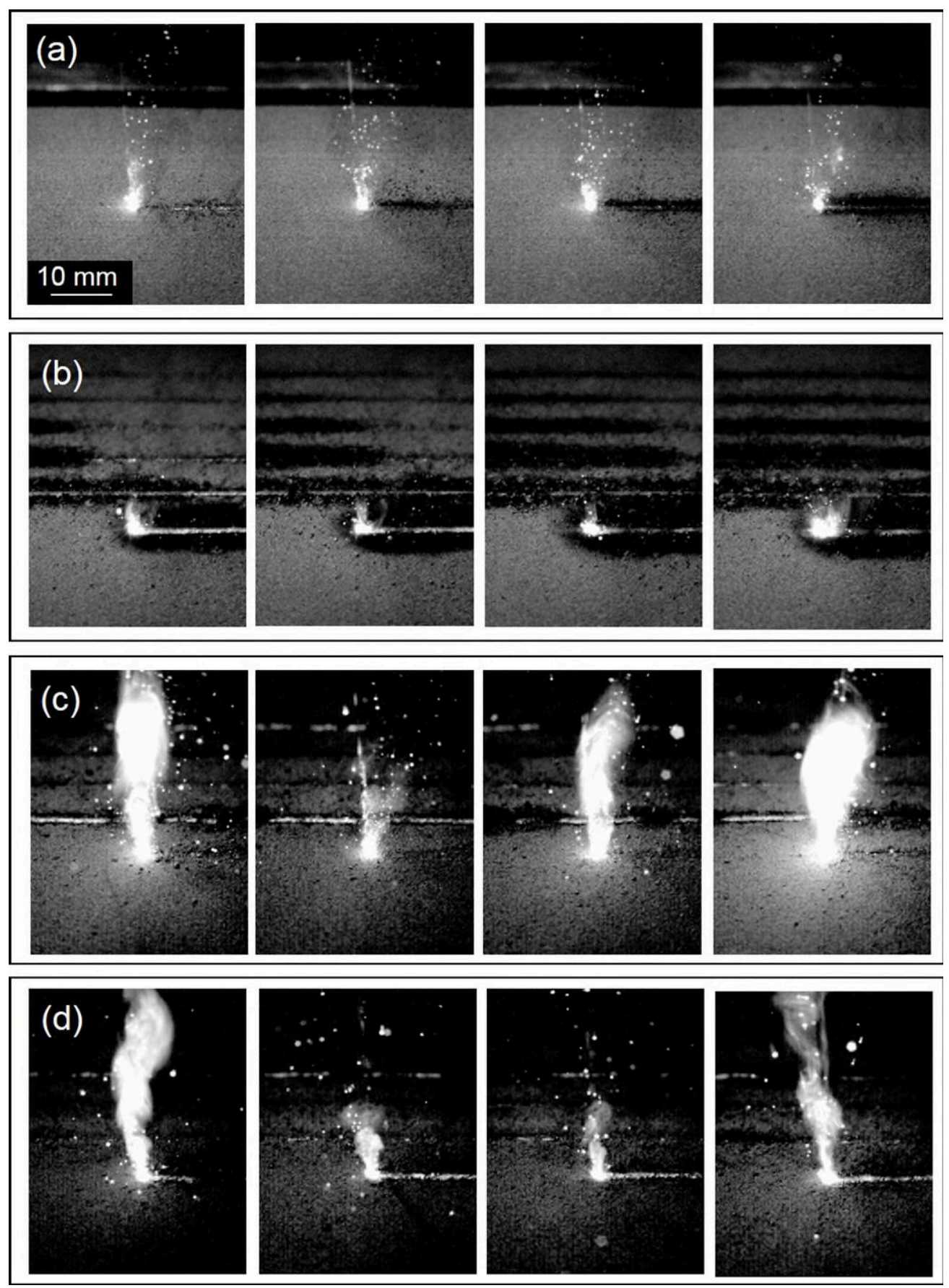

Figure 9. High speed imaging of powder melting under different global shielding conditions and interaction times. Helium global shielding (a) $0.35 \mathrm{~ms}$ and (b) $4 \mathrm{~ms}$. Argon global shielding (c) $0.35 \mathrm{~ms}$ and (d) $4 \mathrm{~ms}$. The time intervals between captions are $93 \mathrm{~ms}$ and $310 \mathrm{~ms}$ for interaction times of 0.35 $\mathrm{ms}$ and $4 \mathrm{~ms}$ respectively. Power density: $7100 \mathrm{~kW} / \mathrm{cm} 2$. 
The combined effect of power density and interaction time (energy density) on penetration depth and bead width for powder melting under global helium atmosphere is shown in Fig. 10. It is clear that penetration depth and bead width increase when the energy density is increased. Moreover, this is done in a repeatable and controlled way.

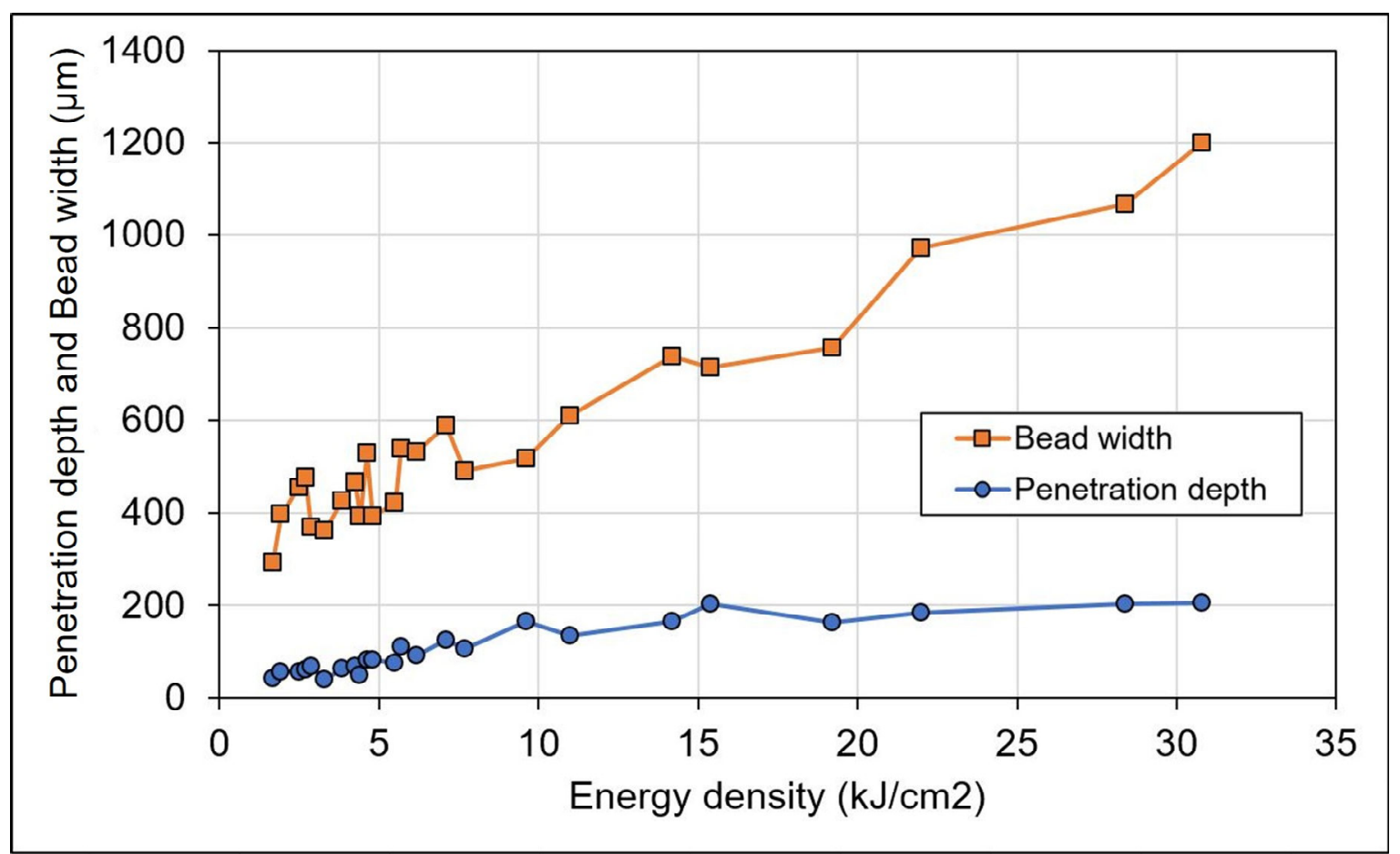

Figure 10. Effect of energy density on penetration depth and bead width. Powder melting under helium global shielding.

The effect of processing parameters on melt height is presented in Fig. 11(a), where it is shown that height also increases with increasing interaction time but it is not greatly influenced by power density changes. Fig. 11 (b), compares the bead area measured from the extracted cross-sections as a function of interaction time and power density for both powder and solid materials. Since the bead area is the amount of material that undergoes melting during processing, this comparison gives a quantitative evaluation of what percentage of the laser energy is utilised by the powder and solid material for melting. For shorter interaction times $(0.35 \mathrm{~ms}$ and $2 \mathrm{~ms})$ the laser energy utilised by the powder and solid is similar. However, when the interaction time increase to $4 \mathrm{~ms}$, powder has a higher melting efficiency as compared to solid. 

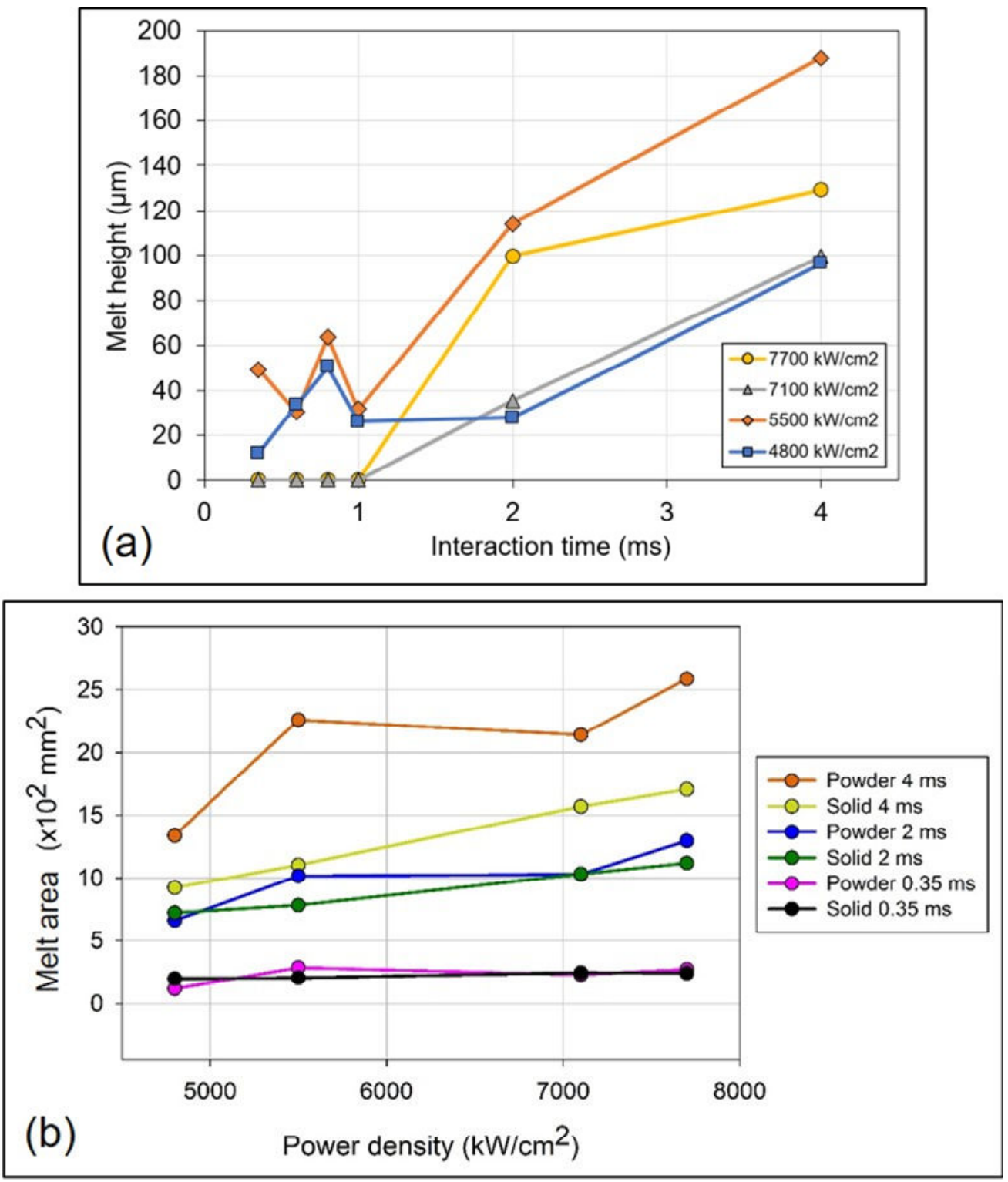

Figure 11. (a) Effect of power density and interaction time on melt height, powder melting. (b) Melt area as function of power density for powder and solid at different interaction times. Powder melting under helium global shielding.

The aspect ratio of all beads deposited under global argon and helium atmosphere and for solid and powder materials are summarised in Fig. 12. The data is plotted as a function of energy density. Aspect ratios lower than 0.4 correspond to conduction regime, while values between 0.4 and 0.6 are considered to be in a transition regime between conduction and keyhole. Values higher than 0.6 are characteristic of keyhole regime [24]. These thresholds have been marked on the plot as red horizontal lines as a reference. In argon, it is clear how 
more melt profiles are in the keyhole and transition regime. On the other hand, in helium, most profiles are in the conduction regime for solid melting while all profiles are in conduction regime for powder melting.
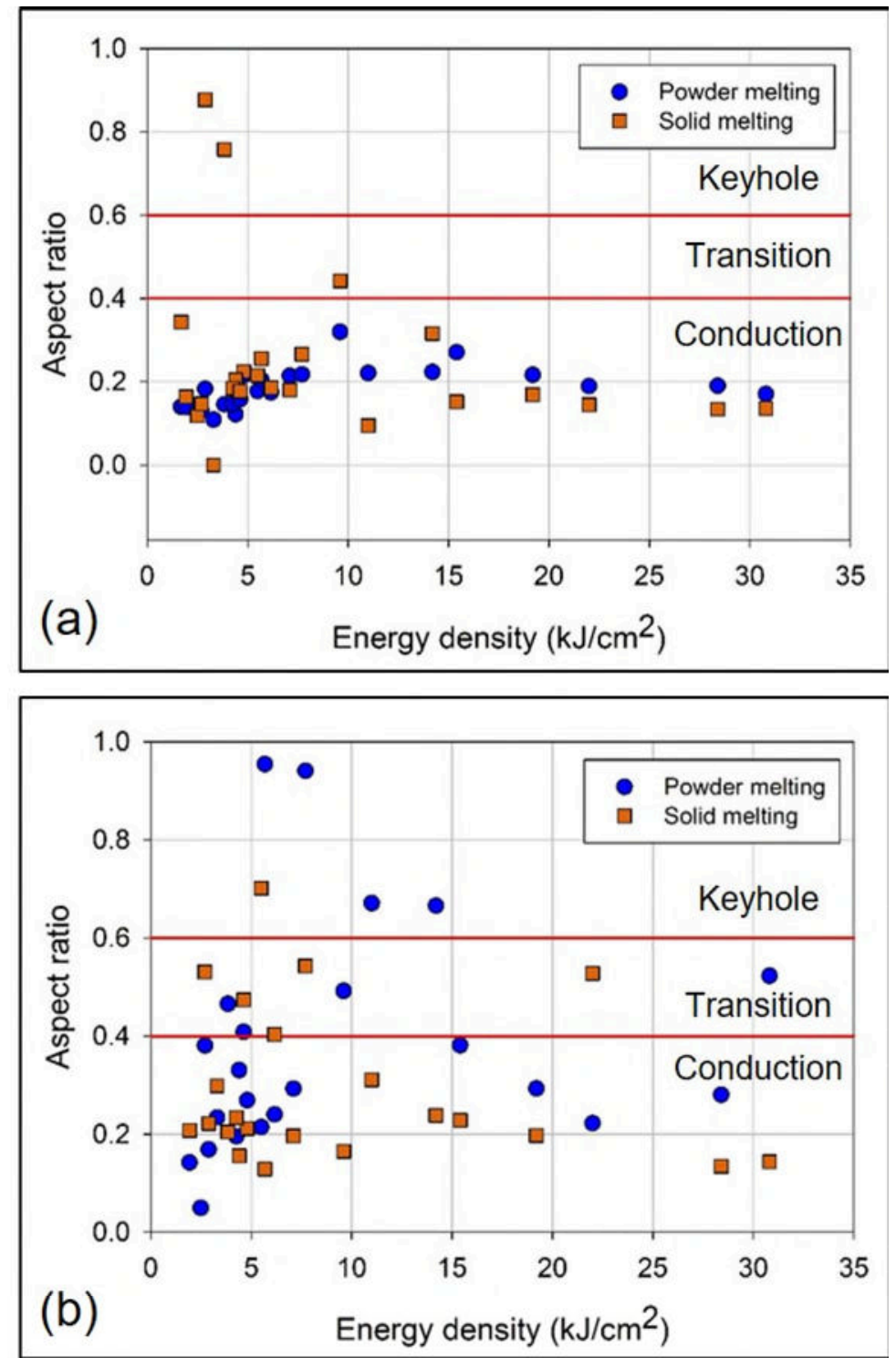

Figure 12. Aspect ratio as a function of specific point energy for powder and solid melting under (a) Helium global shielding and (b) Argon global shielding. Aspect ratio $<0.4$, conduction. $0.4<$ Aspect ratio $<0.6$, transition. $>0.6$, Keyhole. 


\section{Discussion}

\subsection{Plasma plume fluctuations under argon global shielding}

Strong fluctuations on penetration depth and plasma plume characteristics were observed under an argon shielding atmosphere (Fig 4 and Fig 6). The same behaviour was observed for both a single powder layer and solid substrate. Hence, the possibility that such fluctuations are caused by the presence of powder particles can be ruled out. Two important features can be identified for the plasma plume under this condition. First, the generated plasma plume is pulsed in character, and secondly, it reaches a high intensity for some time intervals. The pulsated characteristic of the plasma has been observed before for melting using a continuous wave laser beam. As reported by Mrna and Sarbort [25], this is due to the laser beam absorption by the plasma that fills the keyhole, which causes an increase in temperature and pressure and a further increase in the absorption itself. Once a critical limit is exceeded the plasma expands out of the keyhole generating a burst and the process repeats.

The plasma plume burst is accompanied by a change in melting regime that switches between keyhole, when a high intensity plasma is observed, to conduction when the plasma loses intensity (Fig 5). Heat conduction losses and laser beam-plasma interactions can be suggested as the underlaying mechanism of this observation. As shown by Ayoola et al [26], when a smaller beam size is used, the transition window between conduction and keyhole becomes narrower as consequence of an increased ratio of energy losses to the energy utilised as the laser beam size decreases. Hence, any attempt to increase the input energy to overcome these losses is likely to result in vaporisation and transition to keyhole regime.

As summarized in the introductory section, significant changes in melting stability and bead geometry by using different shielding gases have not been observed before when laser sources with a wavelength of $1.064 \mu \mathrm{m}$ are used. Hence, it would not be expected to find 
such significant changes in these two factors by changing shielding gas from argon to helium for the wavelength of the fibre laser used on this work. It can be suggested that this disagreement is due to the fact that even though a very small percentage of the laser energy is being absorbed by the plasma plume for this wavelength, still the changes are enough to produce a fluctuation between conduction and keyhole. This is due to the fact that for this particular small beam size, even small changes in the input energy can generate a transition between melting modes due to the narrow operating window that exists under this particular condition [26]. An additional factor to consider for the laser beam-plasma plume interactions is the presence of refractive index gradients in the volume surrounding the processing point. Such gradients are formed due to the combination of heated gas, metal vapour and plasma, which are likely to contribute to further process instabilities such as focal shift and lateral laser spot wandering [27].

\subsection{Global argon shielding with cross flow}

It has been shown that for the same range of parameters, an argon gas cross flow helps to stabilise the melting regime (Fig 7). However, even though a more stable process is obtained under this shielding condition, some fluctuations and instabilities of the plasma plume could still be observed. As previously described, when argon is used as the shielding gas, a strong plasma plume forms, which interacts with the laser beam. The gas cross flow has the ability to blow away and deflect the plasma plume which reduces the characteristic length of plasma through which the laser beam has to cross. Also, the fresh gas from the cross flow supplies fresh argon and dilutes the plasma/plume requiring more energy for its ionisation. All these effects minimise the interaction between laser energy and plasma/plume and any focal shift or laser spot wandering that could take place due to the local refractive index gradients. It is also suggested that the inverse bremsstrahlung absorption of the plasma, which is a measure of the amount of laser radiation absorbed by the plasma, could be slightly modified under this condition and therefore the transmittance rate of the laser energy could marginally increase. This would contribute to a better utilisation of the laser 
energy during laser PBF. This behaviour was reported before by $\mathbf{X u}$ et al [28] for laser welding, where it was shown that an increase in shielding gas flow rate led to lower plasma plume energy absorption and to higher transmittance rates when an argon atmosphere was used. However, it should be mentioned that an effective cross flow gas is difficult to set up experimentally, as it needs to be in an optimal and consistent position. If the cross flow is too low with respect to the powder surface it will disturb and scatter the powder particles. On the other hand, if the cross flow is too far from the surface it will not have the desired stabilization effect. The height and brightness of plasma plume was also observed to decrease with decreasing interaction time whilst using the gas cross flow. This could be due to the fact that further ionization of the plasma plume cannot take place as it is constantly being replaced by a "fresh" plume, thus limiting its volume.

\subsection{Melting characteristics under helium global shielding}

The instabilities observed during melting under argon atmosphere were suppressed when helium shielding was used instead of argon (Fig 9). In this case, the plasma plume did not show strong fluctuations in the form of strong bursts and its intensity and size were significantly lower, as compared to ones obtained in argon. Electron temperature and electron density, two important fundamental parameters to describe the state of a plasma plume, can be used to explain this behaviour. As reported by $\mathbf{X u}$ et al [28], the electron temperature and density of the plasma plume in a helium atmosphere will be lower as compared to argon. This is due to the significantly higher ionization potential of helium $(24.46 \mathrm{eV})$ in contrast to argon $(15.68 \mathrm{eV})$. Therefore, a helium atmosphere can effectively prevent further ionization of the plume, which translates into a smaller plasma that will cause less disruption in the laser-powder coupling. A comparison between powder melting in helium and argon (Fig 4 and Fig 8) shows that not only the plasma eruptions are minimised under a helium atmosphere, but also that the melting regime is consistent and is predominantly in conduction mode (Fig 12). This supports the observation that fluctuations of the plasma plume behaviour are directly linked to fluctuations in the melting regime which 
produce very different melt pool geometries. These results demonstrate that control of the plasma plume during laser PBF is key to ensure the stability of the process. Hence, the use of a gas cross flow as a way to stabilize the melting was also explored.

The changes previously described in here, regarding melting stability and particularly the conduction-keyhole fluctuations as a function of shielding gas used for fibre laser, together with the small laser beam used, constitute some of the novel findings of this work as compared to previously reported results in the literature which discuss the role of argon and helium gas on laser welding. Hence, these results imply that the shielding gas combination used during fibre laser PBF is an important factor to consider if the melting behaviour wants to be predicted and controlled in order to increase the robustness of the process.

\subsection{Correlation between bead geometry and processing parameters under helium global shielding}

For a helium atmosphere, as the energy density increases, both penetration and width also increase (Fig 10). As the interaction time gets longer, there is more time for the heat to transfer through the powder material and then by conduction into the substrate. This heat conduction is uniform in all directions in the solid substrate, resulting in hemi-spherical isotherms and melt profiles. However, in some cases, a small P/W aspect ratio of melt geometry can be identified, especially for longer interaction times (Fig 8), where the melt width can reach up to ten times the beam diameter used. According to Ayoola et al [26], the weld width in conduction melting is expected to be proportional to the beam diameter as the latter controls the size of the domain over which the heat is applied. Hence, it was found that beam sizes larger than $1 \mathrm{~mm}$ produce melt geometries of the same width size. In contrast, the small P/W ratios reported in this work suggest that for the small beam size used (100 $\mu \mathrm{m})$, the bead profile is not only controlled by the heat conduction, but also by an additional heat transfer mechanism. When a smaller beam is used, a higher localised laser heating (higher power density) is expected as compared to a larger beam. This produces higher temperature gradients in the surface of the meltpool. Such gradients generate strong 
surface-tension-driven shear forces (Marangoni effect) in the melt pool that widen the bead. Evidence that the geometry of the melt is being partially controlled by this effect is the wavy melt pool boundary that can be observed in some of the cross sections (Fig 13). When the liquid pool obtained is larger than the beam diameter used, heat transfer near the fusion boundary becomes controlled by the liquid flow owing to Marangoni eddies [29]. Such flows produce two recirculation loops in the molten metal. The loop closer to the surface has very high velocities driven by the strong temperature gradient at this region. These loops then cause the liquid in the lower part along the melt centreline to recirculate in the opposite direction, thus creating a wavy fusion boundary [30].

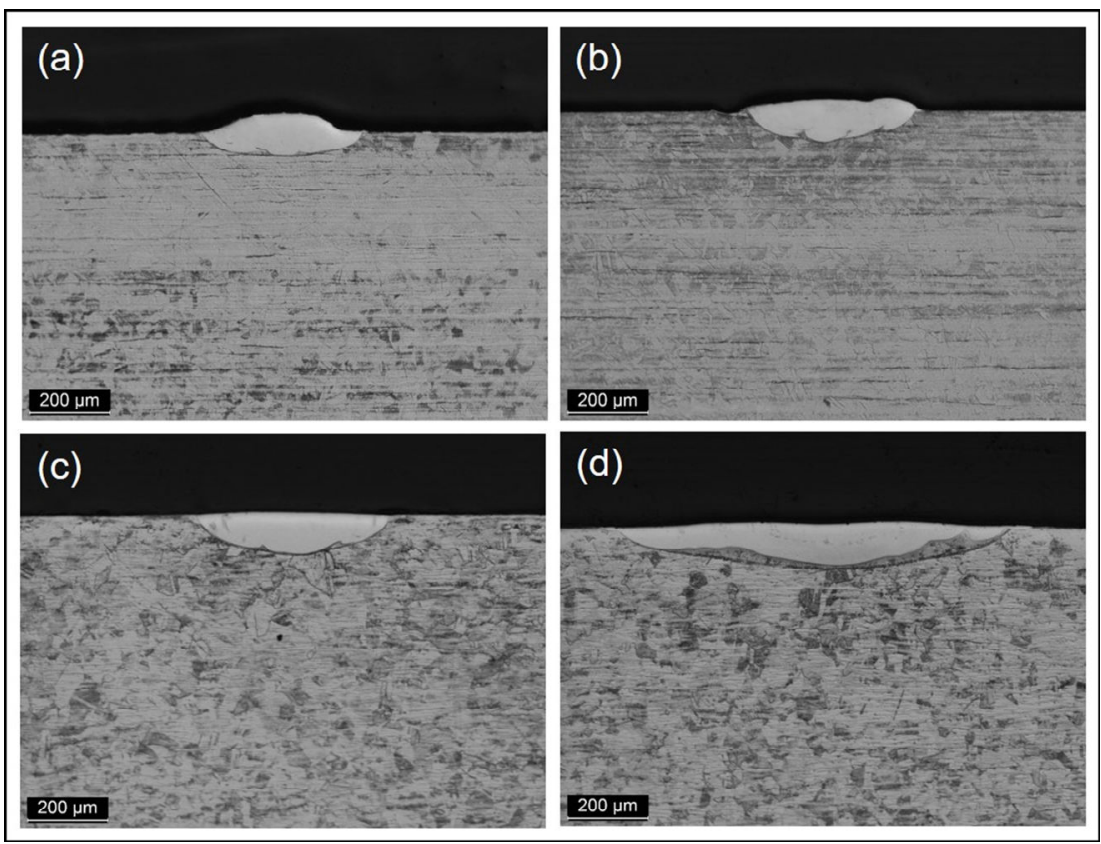

Figure 13. Bead profiles showing a wavy fusion boundary for both powder and solid substrate melting. Helium atmosphere. Power density $5500 \mathrm{~kW} / \mathrm{cm}^{2}$. (a) Interaction time: $0.35 \mathrm{~ms}$ (b) Interaction time: 1 $\mathrm{ms}$ (c) Interaction time: $0.8 \mathrm{~ms}$ (d) Interaction time: $2 \mathrm{~ms}$.

Fig 14 shows the comparisons of the melt bead cross-sections between simulation results and experimental data. With various interaction times, the calculated bead shapes were consistent with the experimental data. Note that the calculated depths are slightly smaller than the measured data, especially for longer interaction times. This is probably because the free surface deformation caused by the Marangoni shear stress and the recoil pressure due 
to the evaporation have not been considered. However, in the context of this work, the model proves that strong Marangoni flow exists in melt pools achieved with this small beam diameter and high power density and this flow expands the melting in the lateral direction beyond the extent of the beam diameter. Fig 15 shows the distributions of temperature and velocity with an interaction time of $4 \mathrm{~ms}$ (The evolution of the temperature and velocity distributions can be seen in the supplementary video provided Video Fig 15). When a high laser power density irradiates the surface of the substrate, the temperature at the centre point increases almost instantaneously to be around the boiling point of the metal (3375 K). Hence, as explained previously, a large temperature gradient is present in the melt pool, causing large Marangoni shear stress on the surface. The maximum speed of the transverse flow at the surface of the melt pool reaches up to $3.5 \mathrm{~m} / \mathrm{s}$ for $4 \mathrm{~ms}$. Thus, a larger width is achieved with longer interaction times within the range tested.
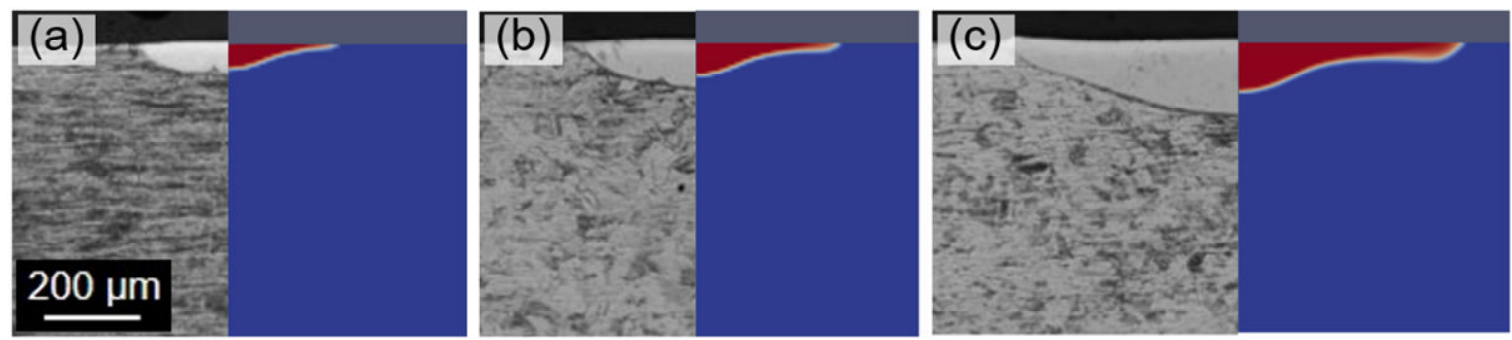

Figure 14. Comparisons of weld cross-sections of solid melting between simulation results and experimental data under different interactive times (a) $0.35 \mathrm{~ms}$; (b) $0.8 \mathrm{~ms}$; (c) $4 \mathrm{~ms}$.

Power density: $5500 \mathrm{~kW} / \mathrm{cm}^{2}$.

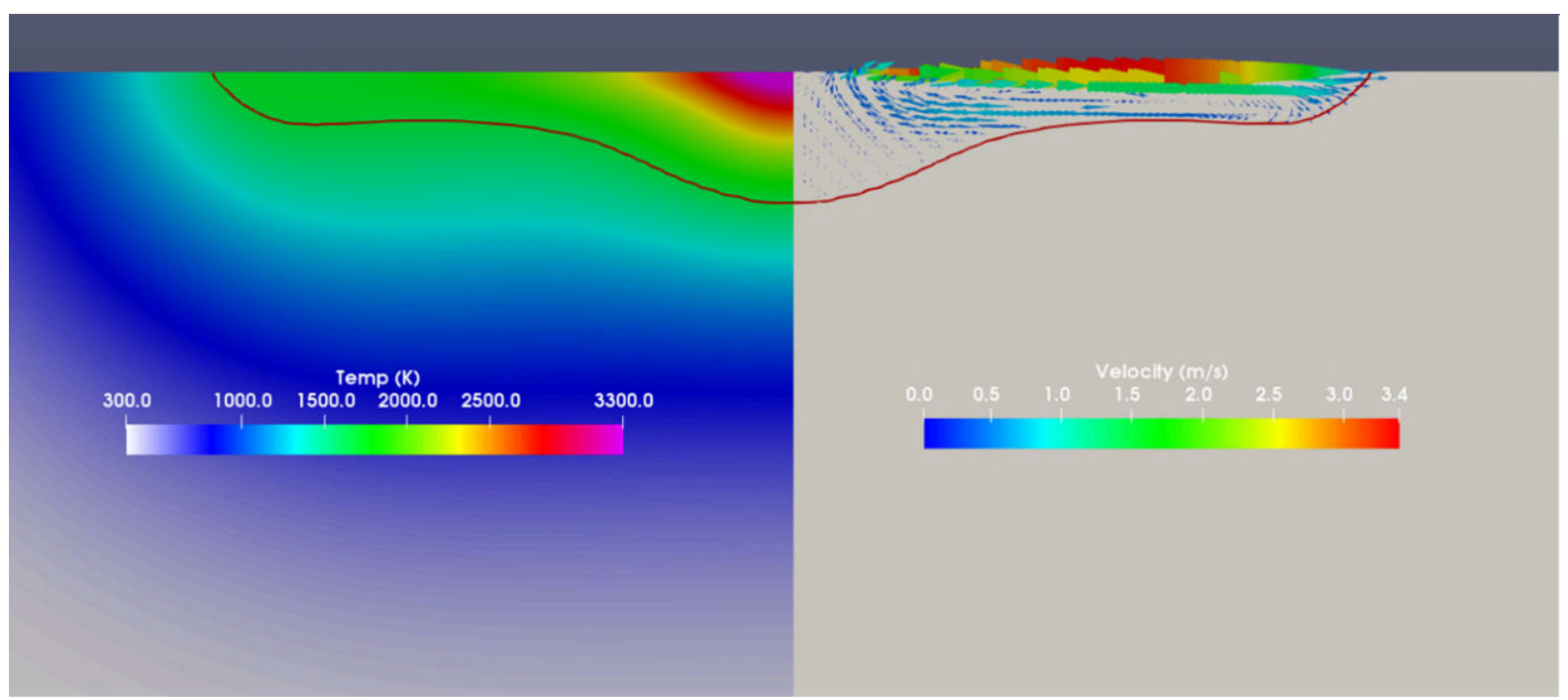

Figure 15. Distribution of the temperature and velocity of solid melting under the interaction time of 4 ms. Power density: $5500 \mathrm{~kW} / \mathrm{cm}^{2}$. 
A closer look to Fig 11 (a) reveals that no powder consolidation is obtained for power densities higher than $5500 \mathrm{~kW} / \mathrm{cm}^{2}$ and interaction times shorter than $1 \mathrm{~ms}$. This is due to a combination of denudation of the powder bed and to high processing speeds that generate additional gas- driven powder particles ejection. For lower power densities and longer interaction times, the melt height increases. As interaction time increases the melt width also increases, improving the chance of the powder particles to be incorporated into the melt pool and increasing the height of the built. The maximum height obtained is around $200 \mu \mathrm{m}$ when a power density of $5500 \mathrm{~kW} / \mathrm{cm}^{2}$ and an interaction time of $4 \mathrm{~ms}$ were used. This value is lower than the powder layer thickness of $250 \mu \mathrm{m}$ used in this work. The observed difference is due to the elimination of voids between the powder particles and powder consolidation once the melting is performed. Similar laser energy utilization is experienced by the powder and the solid substrate for short interaction times (Fig 11 (b)). In contrast, once the interaction time increases, powder melting shows higher energy utilization, which translates into a higher melting efficiency as comparted to solid melting. A longer exposure time to the laser energy means that more time is allowed for absorption to take place. Additionally due to high surface area of powder, laser energy absorption of the powder is higher as compared to the solid substrate. Since the process is predominantly in conduction mode no additional absorption of laser energy associated with the keyhole regime take place. It is shown in this work, that even though laser PBF benefits from high scanning speeds as a way of increasing build rates, using lower scan speeds (longer interaction time) leads to an improvement in the consolidated layer height and a better utilization of the laser energy. Longer interaction times help to achieve higher powder consolidation and better laser energy utilisation. 


\section{Conclusions}

This works provides further insight into the effect of different shielding conditions on the melting behaviour and geometry of single powder layer tracks under different processing conditions. The following conclusions can be drawn:

- For powder and solid substrate, melting under argon atmosphere leads to random fluctuations in melting mode (conduction-keyhole) and a high intensity plasma plume that causes melting instabilities and does not allow control of the bead profile;

- Controlling the plasma plume leads to a more stable melting as it minimizes the laser beam-plasma plume interactions. Both local gas cross flow and helium shielding atmosphere proved to be effective ways of mitigating such instabilities;

- Under helium atmosphere, the strong fluctuations in melting mode and plasma intensity were no longer observed and most achieved beads exhibited profile characteristic of conduction regime. Under this condition, better control of the bead profile was achieved in contrast to argon;

- For melting under helium shielding, penetration and bead width are controlled by energy density;

- Bead width was found to be up to ten times the beam diameter used. A wavy fusion boundary in the analysed profiles and two-dimensional numerical simulations suggest that the width is controlled by strong surface tension driven Marangoni flows under some conditions.

\section{Acknowledgments}

The authors would like to thanks the Engineering and Physical Sciences Research Council (EPSRC) Centre for Innovative Manufacturing in Laser-based Production Processes (Grant No: EP/K030884/1) for the financial support. They would also like to thank Nisar Sha, Flemming Nielsen and Steve Pope for their technical assistance. 


\section{References}

[1] Sun, S., Brandt, M. and Easton, M. (2017) 2 - Powder bed fusion processes: an overview, Laser Additive Manufacturing. Elsevier Ltd. doi: 10.1016/B978-0-08-100433-3.00002-6.

[2] Ngo, T. D. et al. (2018) 'Additive manufacturing ( 3D printing ): A review of materials, methods, applications and challenges', Composites Part B. Elsevier, 143(December 2017), pp. 172-196. doi: 10.1016/j.compositesb.2018.02.012.

[3] Yadroitsev, I. and Smurov, I. (2010) 'Selective laser melting technology: From the single laser melted track stability to 3D parts of complex shape', Physics Procedia, 5(PART 2), pp. 551-560. doi: 10.1016/j.phpro.2010.08.083.

[4] Nezhadfar, P. D., Masoomi, M. and Thompson, S. (2018) 'Mechanical Properties of 17-4 PH Stainless Steel Additively Manufactured under Ar and N2 Shielding Gas', in Solid Freeform Fabrication 2018: Proceedings of the 29th Annual International Solid Freeform Fabrication Symposium - An Additive Manufacturing Conference, pp. 1301-1310.

[5] Pellone, L. et al. (2019) 'Effects of interface gap and shielding gas on the quality of alloy AA6061 fiber laser lap weldings', Journal of Materials Processing Tech. Elsevier, 268(October 2018), pp. 201-212. doi: 10.1016/j.jmatprotec.2019.01.025.

[6] Beck, M. (1995) 'The effect of plasma formation on beam focusing in deep penetration welding with CO2 lasers', Journal of Physics D: Applied Physics, (28), pp. 2430-2442.

[7] Motlagh, N. S. H. et al. (2013) 'The influence of different volume ratios of $\mathrm{He}$ and $\mathrm{Ar}$ in shielding gas mixture on the power waste parameters for Nd: YAG and CO 2 laser welding', Optics and Laser Technology. Elsevier, 54, pp. 191-198. doi:

10.1016/j.optlastec.2013.04.027.

[8] Moscicki, T., Hoffman, J. and Szymanski, Z. (2006) 'Modelling of plasma plume induced during laser welding', Journal of Physics D: Applied Physics, (39), pp. 685-692. doi: $10.1088 / 0022-3727 / 39 / 4 / 014$

[9] Katayama, S., Kawahito, Y. and Mizutani, M. (2010) 'Elucidation of laser welding phenomena and factors affecting weld penetration and welding defects', Physics Procedia, 5(2), pp. 9-17. doi: 10.1016/j.phpro.2010.08.024.

[10] Reisgen, U. et al. (2010) 'Shielding gas influences on laser weldability of tailored blanks of advanced automotive steels', Applied Surface Science. Elsevier B.V., 257(5), pp. 14011406. doi: 10.1016/j.apsusc.2010.08.042.

[11] Kuo, T. and Lin, Y. (2007) 'Effects of Different Shielding Gases and Power Waveforms on Penetration Characteristics and Porosity Formation in Laser Welding of Inconel 690 Alloy', Materials Transactions, 48(2), pp. 219-226. doi: 10.2320/matertrans.48.219.

[12] Bidare, P. et al. (2018) 'Fluid and particle dynamics in laser powder bed fusion', Acta Materialia, 142, pp. 107-120. doi: 10.1016/j.actamat.2017.09.051.

[13] Montgomery, C. et al. (2018) 'Effect of Shield Gas on Surface Finish of Laser Powder Bed Produced Parts', in Solid Freeform Fabrication 2018: Proceedings of the 29th Annual International Solid Freeform Fabrication Symposium, pp. 438-444.

[14] Zhou, B. et al. (2018) 'Materials Science \& Engineering A A study of the microstructures and mechanical properties of Ti6AI4V fabricated by SLM under vacuum', Materials Science \& Engineering A. Elsevier B.V., 724(March), pp. 1-10. doi: 10.1016/j.msea.2018.03.021.

[15] Bidare, $P$ et al. (2018) 'Laser powder bed fusion in high-pressure atmospheres', The international journal of Advanced Manufacturing Technology. The International Journal of 
Advanced Manufacturing Technology, 99(1), pp. 543-555. doi.org/10.1007/s00170-0182495-7

[16] Schniedenharn, M. et al. (2018) 'Visualization of the shielding gas fl ow in SLM machines by space-resolved thermal anemometry', Rapid Prototyping Journal, 24(8), pp. 1296-1304. doi: 10.1108/RPJ-07-2017-0149.

[17] Guo, M. et al. (2019) 'International Journal of Refractory Metals Formation of scanning tracks during Selective Laser Melting ( SLM ) of pure tungsten powder : Morphology , geometric features and forming mechanisms', International Journal of Refractory Metals \& Hard Materials. Elsevier, 79(August 2018), pp. 37-46. doi: 10.1016/j.jirmhm.2018.11.003.

[18] Shi, X. et al. (2016) 'Performance of high layer thickness in selective laser melting of Ti6Al4V', Materials, 9(12), pp. 1-15. doi: 10.3390/ma9120975.

[19] Suder, W. J. and Williams, S. W. (2012) 'Investigation of the effects of basic laser material interaction parameters in laser welding', 24(3), pp. 1-10.

doi.org/10.2351/1.4728136.

[20] Hou, S. (2015) Laser Additive Manufacturing of Embedded 3D Circuit System and Microstructure Manipulation Using Gaussian and Holographic Optical Elements Reconstructed Beams. Loughborough University.

[21] Zhou, J., Tsai, H.-L. and Wang, P. (2006) 'Transport Phenomena and Keyhole Dynamics during Pulsed', Transaction of the ASME, 128, pp. 680-690. doi: 10.1115/1.2194043.

[22] Tan, W., Bailey, N. S. and Shin, Y. C. (2013) 'Investigation of keyhole plume and molten pool based on a three-dimensional dynamic model with sharp interface formulation', Journal of Physics D: Applied Physics, 46, pp. 1-12. doi: 10.1088/0022-3727/46/5/055501.

[23] Pang, S. et al. (2015) '3D transient multiphase model for keyhole , vapor plume, and weld pool dynamics in laser welding including the ambient pressure effect', Optics and Lasers in Engineering. Elsevier, 74, pp. 47-58. doi: 10.1016/j.optlaseng.2015.05.003.

[24] Assuncao, E., Williams, S. and Yapp, D. (2012) 'Interaction time and beam diameter effects on the conduction mode limit', Optics and Lasers in Engineering. Elsevier, 50(6), pp. 823-828. doi: 10.1016/j.optlaseng.2012.02.001.

[25] Mrna, L. and Sarbort, M. (2014) 'Plasma burst in deep penetration laser welding', Physics Procedia, 56, pp. 1261-1267. doi: 10.1016/j.phpro.2014.08.042.

[26] Ayoola, W. A., Suder, W. J. and Williams, S. W. (2017) 'Parameters controlling weld bead profile in conduction laser welding', Journal of Materials Processing Technology. Elsevier, 249(August 2016), pp. 522-530. doi: 10.1016/j.jmatprotec.2017.06.026.

[27] Bidare, $\mathrm{P}$ et al. (2018) 'Laser powder bed fusion at sub-atmospheric pressures', International Journal of Machine Tools and Manufacture. Elsevier Ltd, 130-131(March), pp. 65-72. doi: 10.1016/j.jmachtools.2018.03.007.

[28] Xu, J. et al. (2019) 'Effect of shielding gas on the plasma plume in pulsed laser welding', Measurement. Elsevier Ltd, 134, pp. 25-32. doi: 10.1016/j.measurement.2018.10.047.

[29] Drezet, J.-M. and Mokadem, S. (2006) 'MARANGONI CONVECTION AND

FRAGMENTATION IN LASER TREATMENT', 508, pp. 257-262. doi: 10.4028/www.scientific.net/MSF.508.257.

[30] Arora, A., Roy, G. G. and Debroy, T. (2009) 'Unusual wavy weld pool boundary from dimensional analysis', Scripta Materialia. Acta Materialia Inc., 60(2), pp. 67-70. doi:

10.1016/j.scriptamat.2008.08.035. 
2020-05-26

Effect of shielding conditions on bead profile and melting behaviour in laser powder bed fusion additive manufacturing

\author{
Caballero, Armando
}

Elsevier

Caballero A, Suder W, Chen X, et al., (2020) Effect of shielding conditions on bead profile and melting behaviour in laser powder bed fusion additive manufacturing. Additive Manufacturing, Volume 34, August 2020, Article number 101342

https://doi.org/10.1016/j.addma.2020.101342

Downloaded from Cranfield Library Services E-Repository 